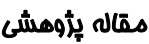

\section{نابرابرى قابل اجتناب اقتصادى -اجتماعى در توزيع سلامت روان در شهر تهران: رويكرد استاندارد سازى شاخص تجمعى}

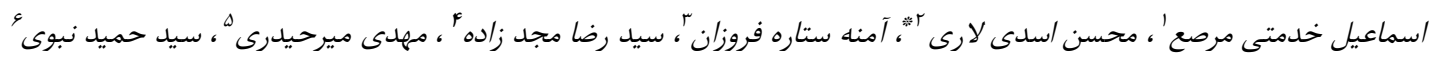

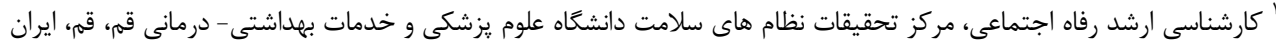

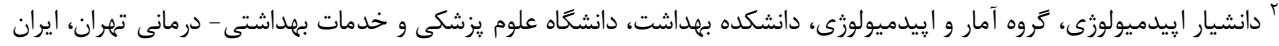

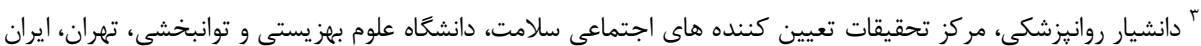

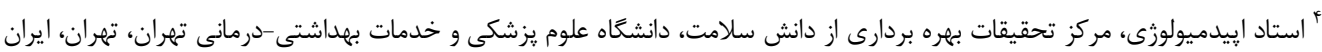

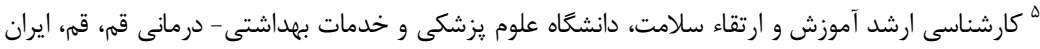

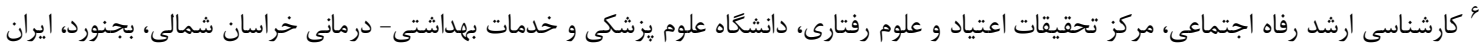

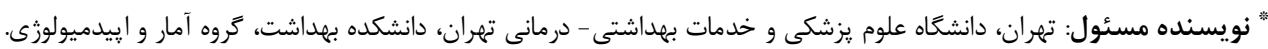

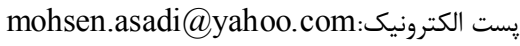

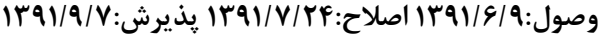

جكيده

زمينه و هدف: توزيع نابرابر سلامت در جوامع انسانى يكى از جالش هاى عمده نظام هاى سلامت است. مطالعه حاضر باهدف سنجش

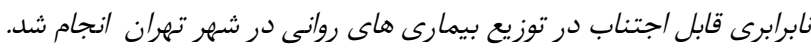

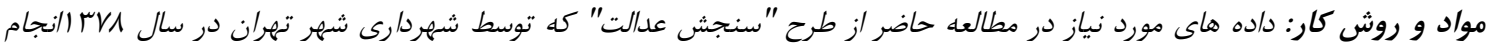

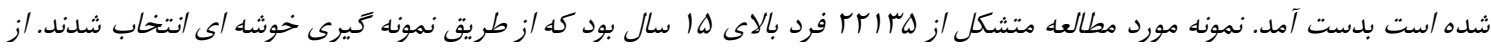

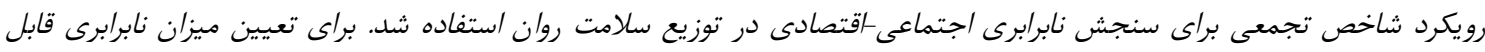

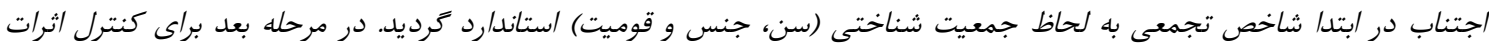

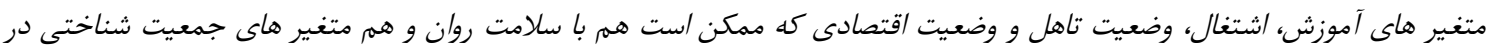

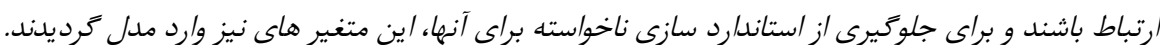

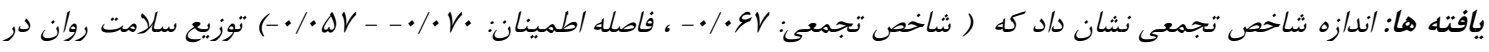

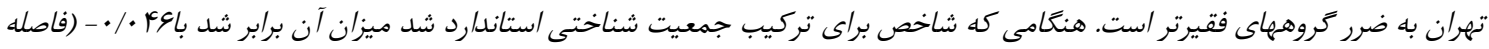

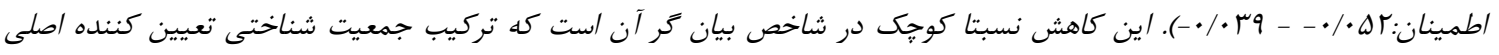

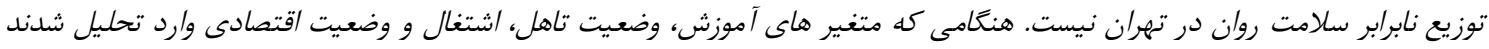

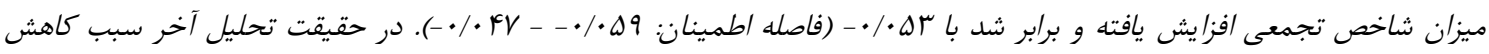

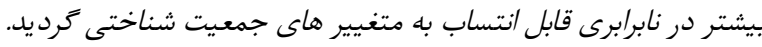

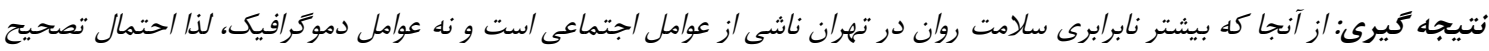

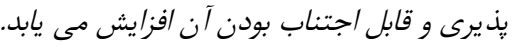
وازه هاى كليدى:استاندارد سازى، سلامت روان، شاخص تجمعى، نابرابرى قابل اجتناب ئنس

بيشتر آشكار مى گردد كه سلامت روان براى بهزيستى مقدمه

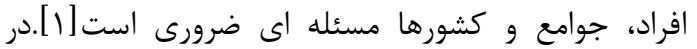
براى تمامى افراد، سلامت جسمى، روانى و اجتماعى اصل سلامت، بدون سلامت روان مفهومى ييدا نمى حياتى بوده و خطوط درهم تنيده زندگى را تشكيل مى

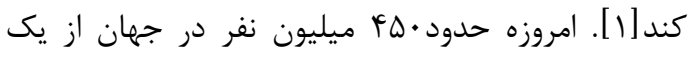
دهند. همزمان با افزايش درك ما از اين رابطه، اين امر 
اما نكته اصلى اين است كه نابرابرى ها در سلامت روانى را

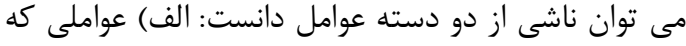

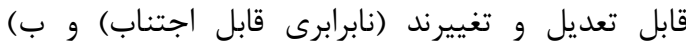

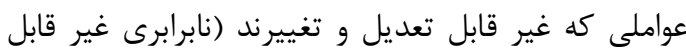
اجتناب). از عوامل قابل تعديل مى توان به موقعيت اجتماعى و اقتصادى فرد، جنسيت، سطح آموزش، سطح

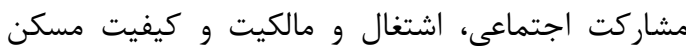

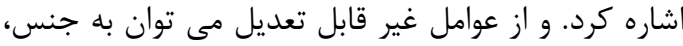

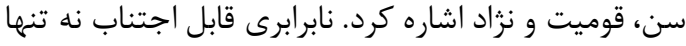
نابرابرى بلكه نوعى بى عدالتى نيز است؛ زيرا كه ساخته

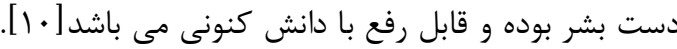
اگر در يك جامعه مشخص شود كه نابرابرى هاى سلامت روان بيشتر ناشى از كدام عوامل است، آنغاه سئ سياست كذارى ها و استراتزى هاى لازم روشن شده و اقدامات بهترى براى بهبود عدالت در سلامت روان در آن آن جامعه

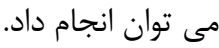
تحقيق حاضر در حقيقت به دنبال انجام جنين كارى در مورد نابرابرى هاى سلامت روان است. يس از سنجش

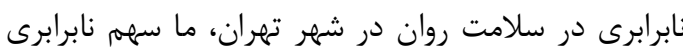

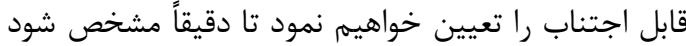
شرايط اجتماعى زندگى در شهر تهران مسئول جه ميزان

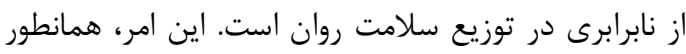

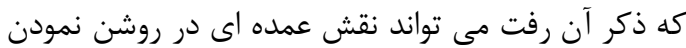
مسير سياست كذارى سلامت روان در اين شهر داشته

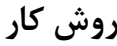

مطالعه حاضر با استفاده از داده هاى يِيمايش "سنجش

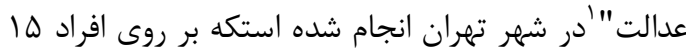

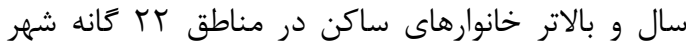

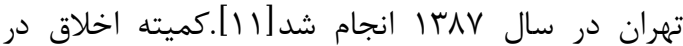
يزوهش دانشكاه ايران و همجنين مركز تحقيق و برنامه

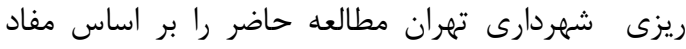
اعلاميه هلسينكى مورد بررسى قرار داده و تاييد نموده اند. در پيمايش مذكور از روش نمونه گيرى طبقه بندى شده
اختلال روانى يا رفتارى رنج ميبرند[1]]. اين بيمارى ها

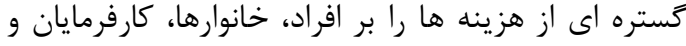

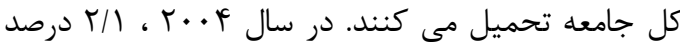

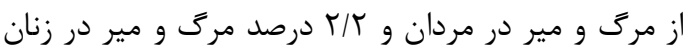

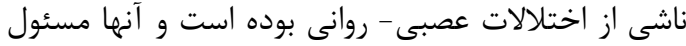
يك سوم سالهاى از دست رفته ناشى از بيمارى(YLD)

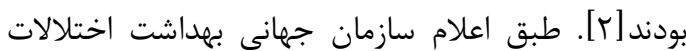

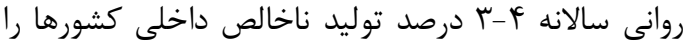

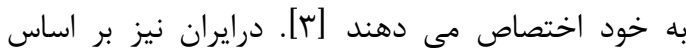

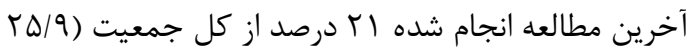

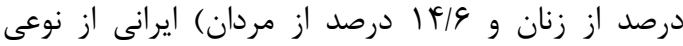

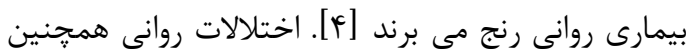

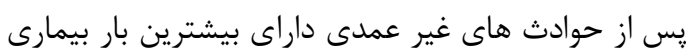
ها در كشور مى باشند [هادة] اما از سوى ديگر، و از نظر عدالت در سلامت، در همه الفها جوامع اين اختلالات روانى به طور نامتناسبى كروهيهاى مختلف اجتماعى - اقتصادى را تحت تاثير قرار مي إنى دهند. در حقيقت اين گروههاى ضعيف تر به لحاظ اجتماعى و

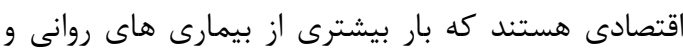
عواقب آنها را تجربه مى كنند و نوعى از نابرابرى در در توزيع

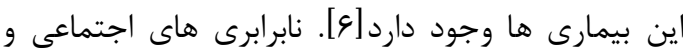

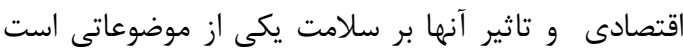
كه امروزه به شدت مورد توجه و تمركز است زيرا كه ارتقاء سلامت در جوامع بيمار بسيار سخت تر از كمك به افراد

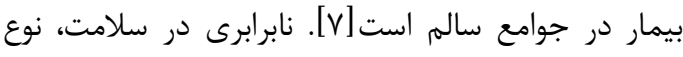
خاصى از تفاوت در سلامت است كه در آن كروه هاى داى اجتماعى آسيب يذير يا كروههايى كه به طور دائم شرايط

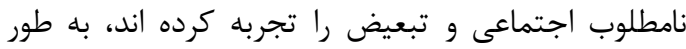
نظام مندى سلامت وخيم تر يا ريسك هاى سلامت إنداء

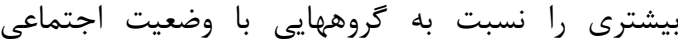

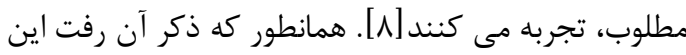
رابطه بين سلامت و شرايط اجتماعى و توزيع نابرابر سلامت دلالت هاى بسيار مهمى براى سلامت روان دارند و

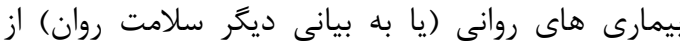

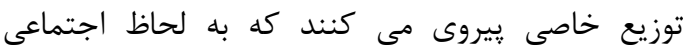
الكوبندى شده است [9].
1.Urban Health Equity Assessment and Response Tool (Urban HEART) Survey 
هاى وارده تبيين كرده و بدين ترتيب به عنوان شاخص وضعيت اقتصادى هر فرد (خانوار) در نظر كرفته مى شودان در واقع اين مولفه براى هر خانوار يك نمره ارائه مى دهد

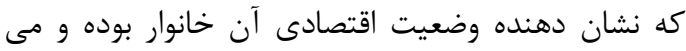

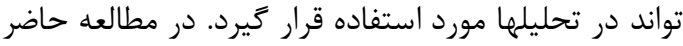

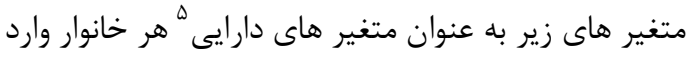

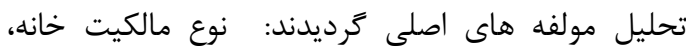

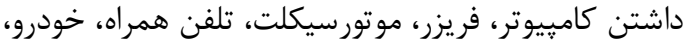
آشيزخانه، داشتن حمام، تلفن ثابت، داشتن توالت، تعداد

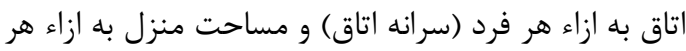

$$
\text { فرد (سرانه مساحت). }
$$

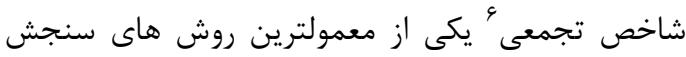

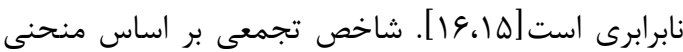

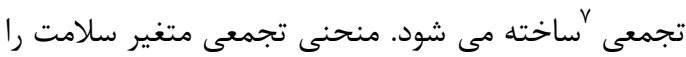

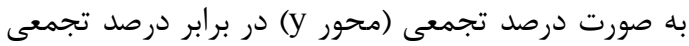

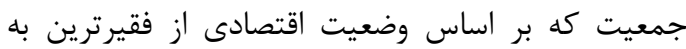
ثروتمندترين مرتب شده اند(محور X)، قرار مى دهد. همه افراد فارغ از وضعيت اقتصاديشان از سطح يكسانى از

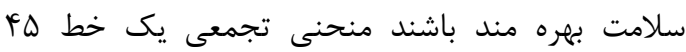

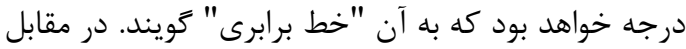
اگر متغير سلامت تجمع بيشترى در ميان افراد فقير داشته باشد، منحنى تجمعى در بالاى خط بردي برابرى قرار

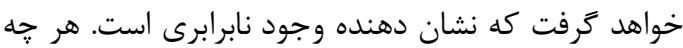
منحنى تجمعى از خط نابرابرى بيشتر فاصله بخيرد، ميزان

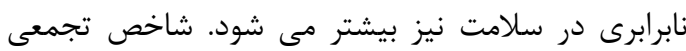

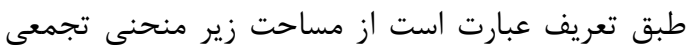
ضربدر دو. بنابراين در صورتى كه خط برابرى و منحنى لقدي تجمعى بر هم منطبق باشند، شاخص تجمعى برابر صفر درائ

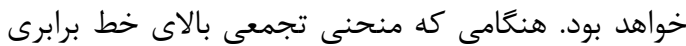

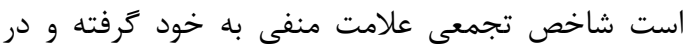
صورتى كه در يايين خط برابرى باشد علامت مثبت به

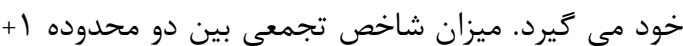

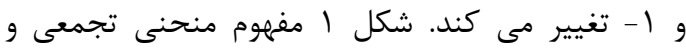
شاخص تجمعى را به صورت شماتيك نشان مى دهد.

5 .Asset Variables

6. Concentration Index (CI)

7. Concentration Curve
جند مرحله اى خوشه اى'براى انتخاب نمونه هاستفاده

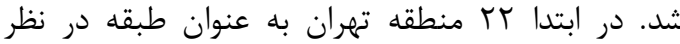
كَرفته شدند (نمونه گَيرى طبقه ایى)، سيس به ريه روش نمونه

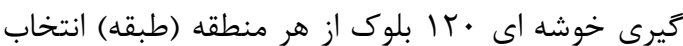

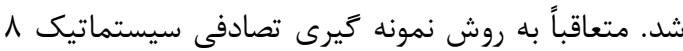

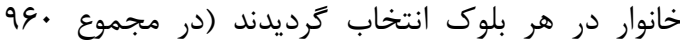

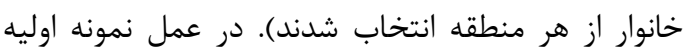

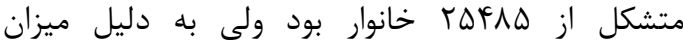

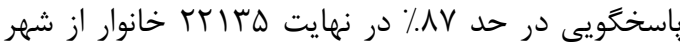

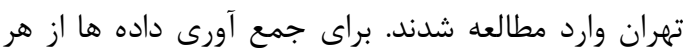

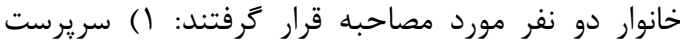

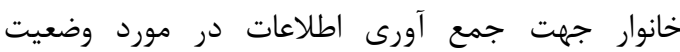
اقتصادى خانوار و r r) فرد انتخاب شده از طريق نمونه كيرى براى تكميل يرسشنامه هاى طرح كه بخشى از آن يرسشنامه سلامت روان بود. يرسشنامه مورد استفاده براى شناسايى موارد محتمل برد

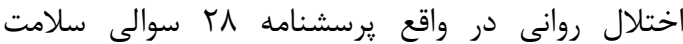

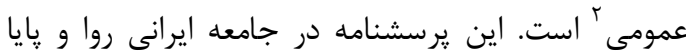

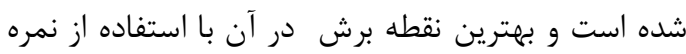

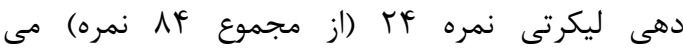

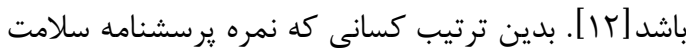

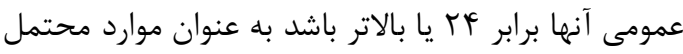

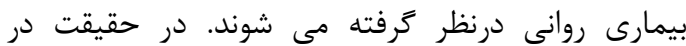

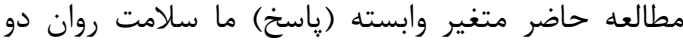

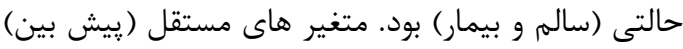
نيز عبارت بودند از سن، جنس، قوميت، سطح آموزش و ودئ وضعيت اشتغال و وضعيت اقتصادى. براى سنجش وضعيت اقتصادى از روش تحليل مولفه هاى

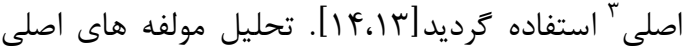

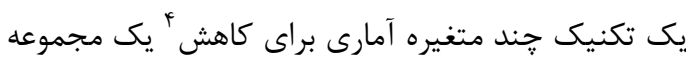

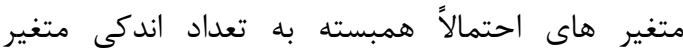
ناهمبسته است كه به آنها مولفه هاى اصلى كويند. مولفه اول حاصل از تحليل بيشترين واريانس را در ميان متغير

1.Stratified multistage cluster sampling

2. General Health Questionnaire- 28 (GHQ28)

3 .Principal Component Analysis (PCA) 4 .Reduction 

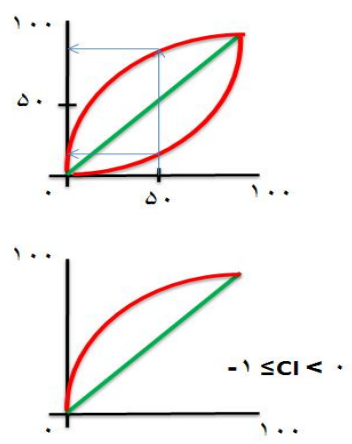
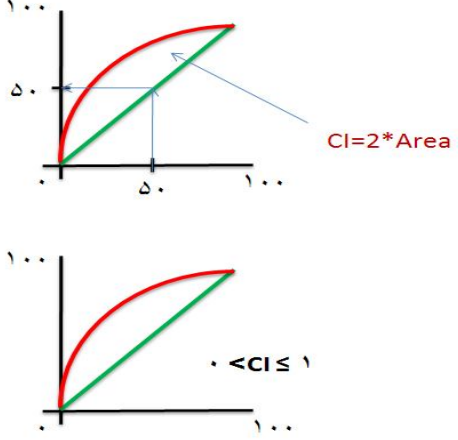

شكل 1: مفهوم شماتيك منحنى و شاخص تجمعى

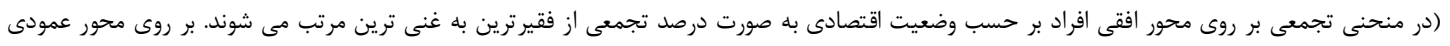

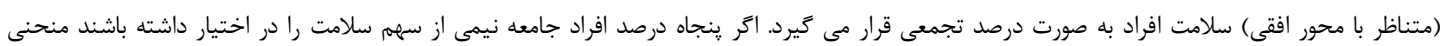

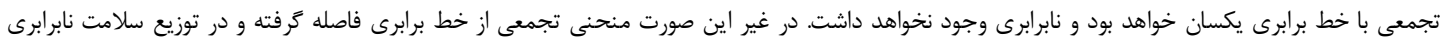

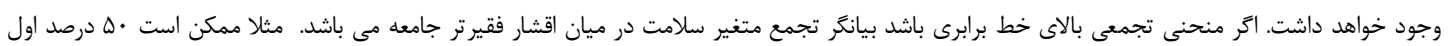

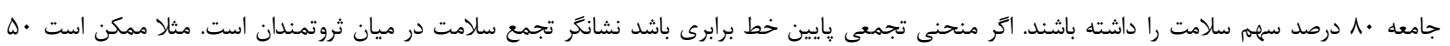

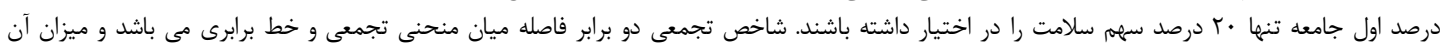

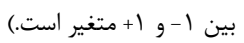

كذارى ها تفكر نمود. استاندارد سازى شاخص هاى سنجش نابرابرى يكى از روش هاى انجام جنين تمايزى

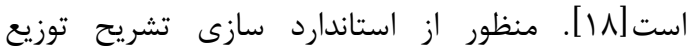
اجتماعى-اقتصادى سلامت مشروط به ثابت بودن اثرات

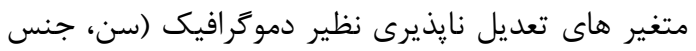

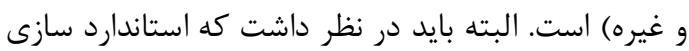
در صورتى سودمند است كه متغير هاى تحت استاندارد هم با موقعيت اجتماعى اقتصادى و هم با سلامت در ارتباط باشند.

دو روش كاملا متفاوت براى استاندارد سازى وجود دارد:

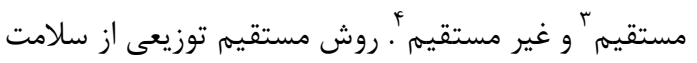

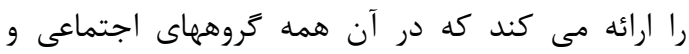

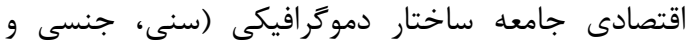
غيره) يكسانى دارند. البته با اين وجود هر زروه دارئاى

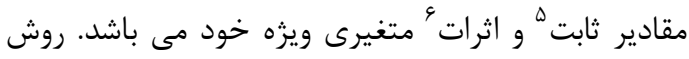

\section{3 .Direct}

4. Indirect

5 .Intercept

6 .Effects
به طور خلاصه مى توان فرمول شاخص تجمعى را به

$$
\mathrm{C}=\frac{2}{\mu} \operatorname{cov}\left(Y_{i}, R_{i}\right)
$$

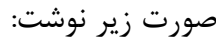

كه در آن اقتصادى فردنام و بر عبارت است از ميانكَين سلامت و

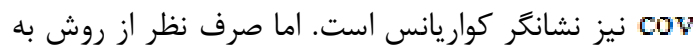

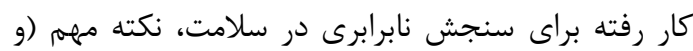

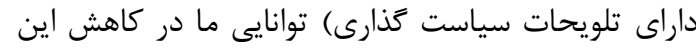

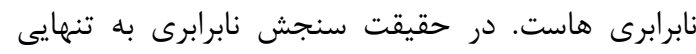

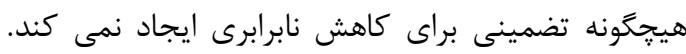

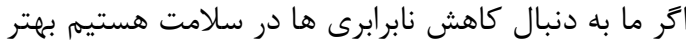

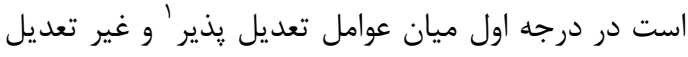

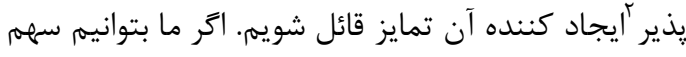

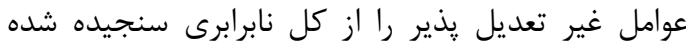
بدست آوريم راحت تر مى توان در مورد نوع سياست

\section{Modifiable}

2. Non-modifiable 
مخدوش كننده (در افراد)(

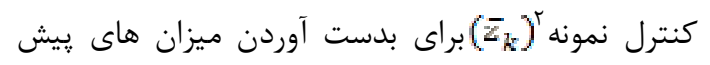
بينى شده ّم متغير سلامت $\hat{y}_{i}^{X}=\alpha+\sum_{j} \hat{\beta}_{j} x_{j i}+\sum_{k} \hat{\gamma}_{k} \bar{z}_{k i}+\varepsilon_{i}$

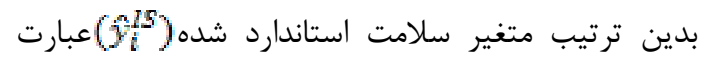
خواهد بوداز تفاوت ميان سلامت واقعى و پيش بيش بينى شده

$$
\text { بعلاوه ميانكين نمونه: } \hat{y}_{i}^{I S}=y_{i}-\hat{y}_{i}^{X}+\bar{y}
$$

توزيع

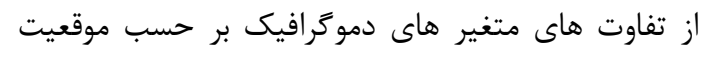

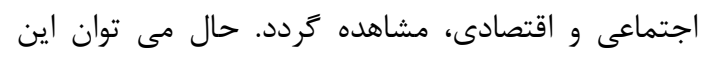

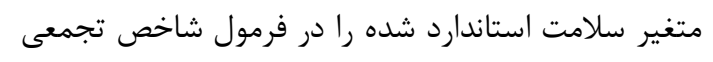

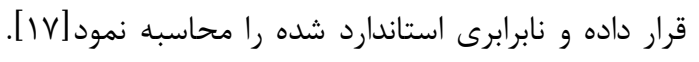

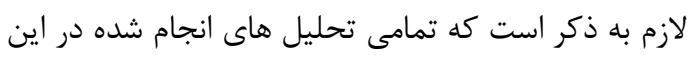

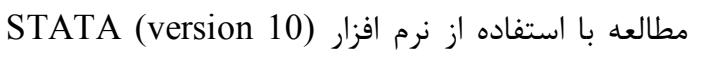

$$
\text { انجام شد [11]]. }
$$

يافته ها

ويزگى هاى نمونه مورد مطالعه و همجناتين ميزان

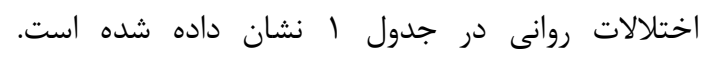

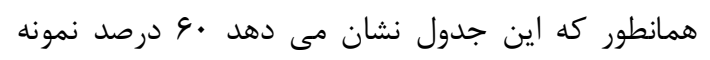

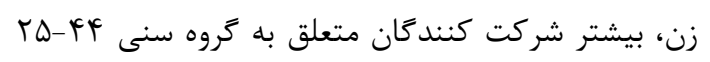

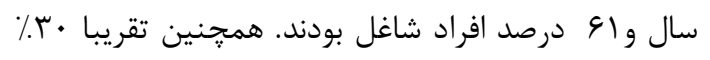

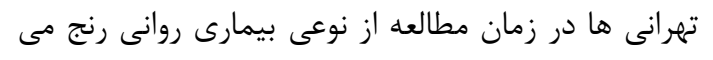

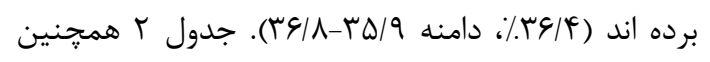

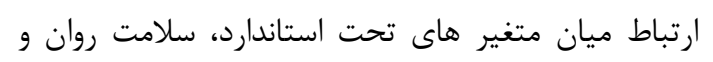

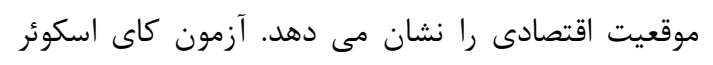

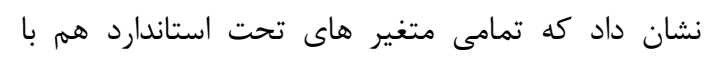

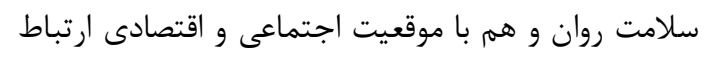

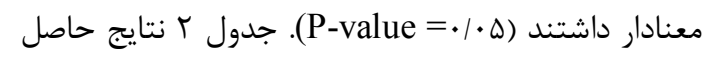

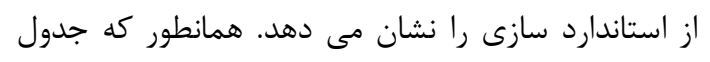

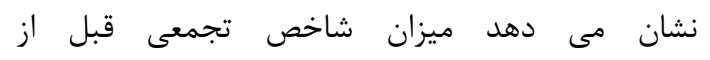

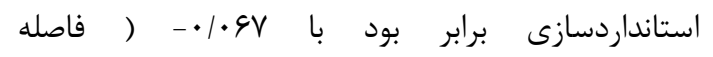

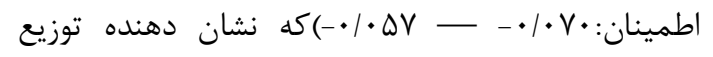

\section{Sample}

3.X-expected
غير مستقيم توزيعى از سلامت را تفسير مى كند كه در درا

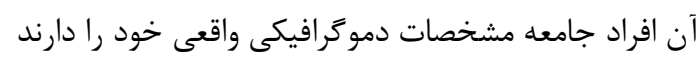

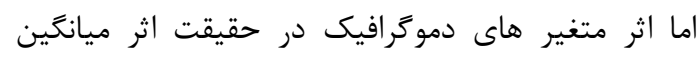

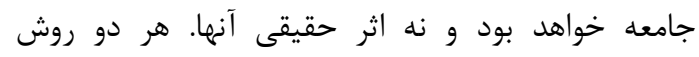
استانداردسازى را مى توان از طريق تحليل رگرسيون انجام

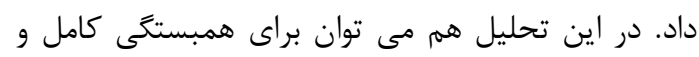

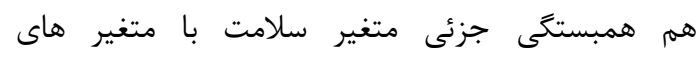

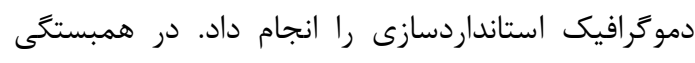

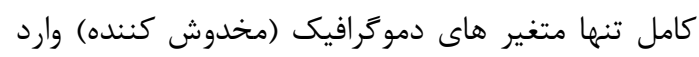

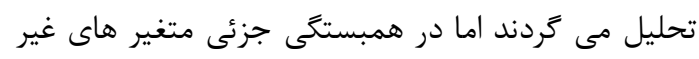

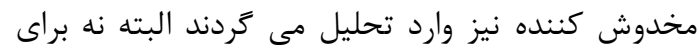

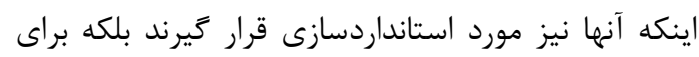

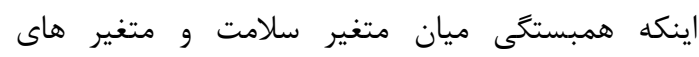

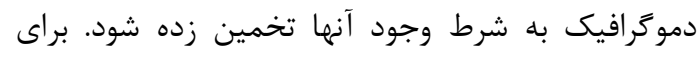

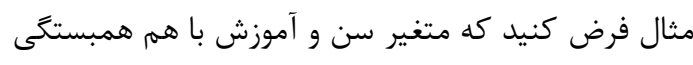

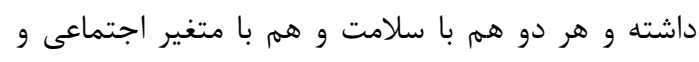
اقتصادى همبستخى داشته باشند. اخر استانداردسازى تنها

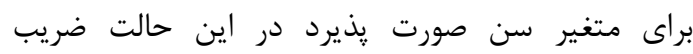
رخرسيونى سن نشان دهنده همبستخى مشترك با آموزش

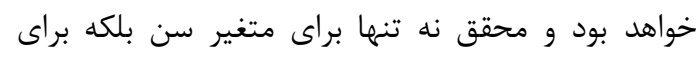

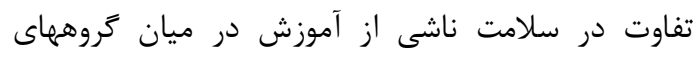

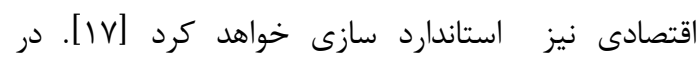
مطالعه حاضر متغير هاى كنترل عبارت خواهند بود از وضعيت اقتصادى، سطح سواد، وضعيت اشتغال و وضعيت هاضي

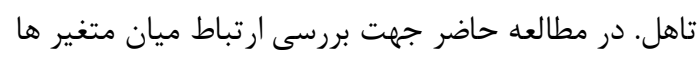
محققين از آزمون كاى اسكوئر بهره كرفتندي

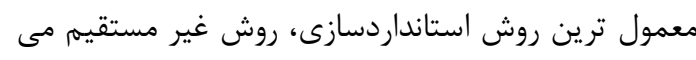

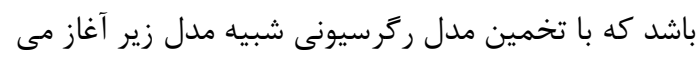

$$
y_{i}=\alpha+\sum_{j} \beta_{j} x_{j i}+\sum_{k} \gamma_{k} z_{k i}+\varepsilon_{i}
$$

كه در آن

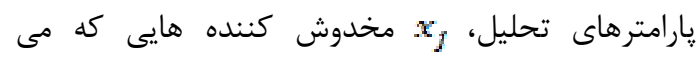

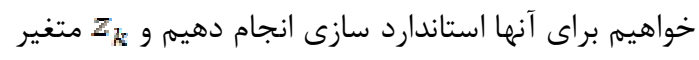

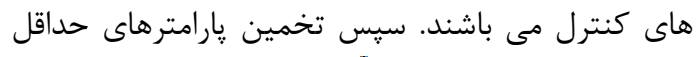

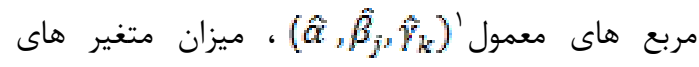

\section{1 .Ordinary Least Squares (OLS)}


جدول 1: ويزگى هاى نمونه مورد مطالعه ، شيوع اختلالات روانى و ارتباط ميان متغير هاى مطالعه

\begin{tabular}{|c|c|c|c|c|c|}
\hline $\begin{array}{l}\text { P-value } \\
\text { (وضعيت }\end{array}$ & $\begin{array}{c}\text { P-value } \\
\text { (سلامت روان) }\end{array}$ & تعداد افراد با & تعداد افراد & \multicolumn{2}{|c|}{ متغير } \\
\hline \multirow{2}{*}{$\cdot \cdot \cdot r$} & $<\cdot 1 \cdot \cdot 1$ & $(\Gamma \cdot)$ Y & $\wedge 9 \Delta \Delta$ & مرد & جنسيت \\
\hline & & $(Y \cdot / D) \Delta T V T$ & 落. & زن & \\
\hline \multirow[t]{3}{*}{$<\cdot 1 \cdot \cdot 1$} & $<\cdot 1 \cdot \cdot 1$ & $(M F / F)$ FFAF & r & فارس & قوميت \\
\hline & & $(Y \cdot / 8)$ Y T QD & $\Delta G Y \Delta$ & ترك & \\
\hline & & 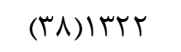 & rFVA & ديخر & \\
\hline \multirow[t]{4}{*}{$<\cdot 1 \cdot \cdot 1$} & $<\cdot 1 \cdot \cdot 1$ & $(Y / / D) \mid G F T$ & $\Delta T \cdot 1$ & $\mid \Delta-Y F$ & كروه سنى \\
\hline & & (r/D/D)rr. & $9 \Delta \Delta \varphi$ & $r \Delta-F Y$ & \\
\hline & & $(५ q / \vee)) १ \wedge ६$ & fq95 & $F \Delta-G F$ & \\
\hline & & $(0 \cdot / 1) 119 V$ & rMAg & $\geq 90$ & \\
\hline \multirow[t]{2}{*}{$<\cdot \mid \cdot \cdot 1$} & $<\cdot 1 \cdot \cdot 1$ & $(T Y / G)$ FFVD & $I r v \cdot V$ & 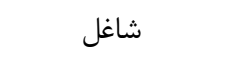 & وضعيت اشتغال \\
\hline & & $(f / / \Delta) r \Delta \cdot f$ & NFTA & بيكار & \\
\hline \multirow[t]{3}{*}{$<\cdot 1 \cdot \cdot 1$} & $<\cdot 1 \cdot \cdot 1$ & $(r V / T) \mid r \cdot \Lambda$ & pVqq & دانشخاهى & سطح آموزش \\
\hline & & $(r \vee) \Delta \varphi) ।$ & |Q|T| & تحصيلات غير & (سواد) \\
\hline & & $(F q / \Delta) \mid l \cdot V$ & DTMA & بى سواد & \\
\hline \multirow[t]{4}{*}{$<\cdot 1 \cdot \cdot 1$} & $<\cdot 1 \cdot \cdot 1$ & (YY/G)\&GT & 1914. & متاهل & وضعيت تاهل \\
\hline & & $(q q / q)) \cdot q q$ & rIDF & بيوه & \\
\hline & & $(\mathcal{F} / G) \backslash q$ r & rqv & مطلقه & \\
\hline & & $(T r / F) \mid F F$ & fef & مجرد - & \\
\hline \multirow[t]{6}{*}{-} & $<\cdot 1 \cdot \cdot 1$ & $(r N / \Delta) I T \Delta T$ & prqu & ثروتمندترين & وضعيت اقتصادى \\
\hline & & سTKR/F)|FT & qr人q & دومين ينجك & (ينجك اقتصادى) \\
\hline & & & & ثروتمند & \\
\hline & & $(\Gamma \Delta / \varphi) \backslash \Delta \varphi$. & fq.r & ينجك ميانه & \\
\hline & & $(r q / V) \mid V F r$ & FrAV & دومين ينجك فقير & \\
\hline & & $(F V) Y I F \Lambda$ & r & فقيرترين & \\
\hline
\end{tabular}

نابرابرى هاى موجود در سلامت روان مى باشند كه غير

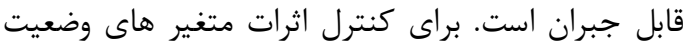
اقتصادى، سطح سواد، وضعيت اشتغال و وضعيت تاهل، اين متغير ها هم وارد مدل كرديدند. اين متغير ها نيز با وناد

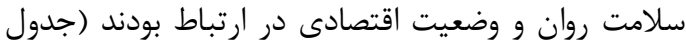
1). جالب است هنخامى كه متغير هاى فوق را به به تحليل

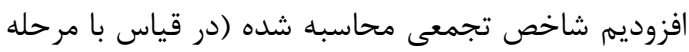

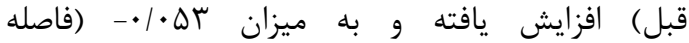
|طمينان:ه9•|•
نابرابر بيمارى هاى روانى (سلامت روان) به ضرر (به سود)

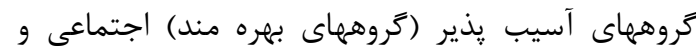

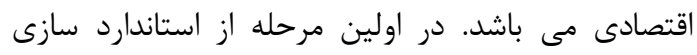
متغير هاى سن، جنسيت و قوميت وارد مدل كرديدند. ميزان شاخص تجمعى ڤֶ از اين استاندارد سازى برابر

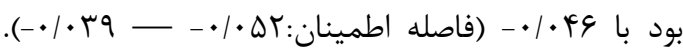
تفاوت ميان اين ميزان استاندارد شده و ميزان اوليه

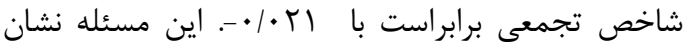

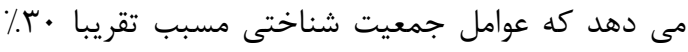


جدول r: نتايج حاصل از استاندارد سازى شاخص تجمعى

\section{استاندارد شده (فاصله اطمينان هذ٪)}

\begin{tabular}{|c|c|c|c|}
\hline سن +جنسيت + قوميت + متغير هاى كنترل & سن + جنسيت + قوميت & استاندارد نشده(فاصله اطمينان & \\
\hline (وضعيت اقتصادى، آموزش، وضعيت تاهل، & & $(\% 9 \Delta$ & \\
\hline 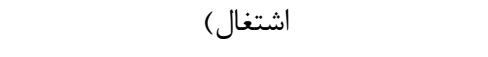 & & & سلامت روان \\
\hline$-\cdot / \cdot \Delta r(-\cdot / \cdot q V--\cdot / \cdot \Delta q)$ &.$- / .4 q(-. / . r q--. / . \Delta r)$ & $-\cdot 1 \cdot 9 \mathrm{~V}(-\cdot 1 \cdot \Delta \mathrm{V}--\cdot 1 \cdot \mathrm{V} \cdot)$ & \\
\hline
\end{tabular}

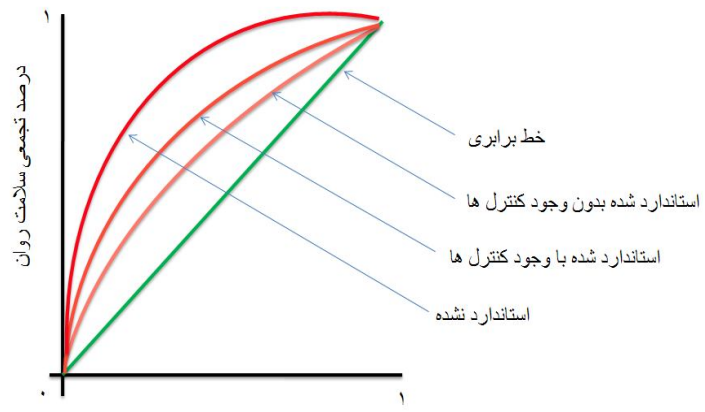

درصد تجمعى افراد نمونه از فقيرترين باه غنى تزين

شكل ז: شكل شماتيك شاخص تجمعى در سه حالت استاندارد نشده، استاندارد شده بدون و با وجود متغيرهاى كنترل

يذيرتر جامعه وجود دارد. استاندارد سازى شاخص تجمعى

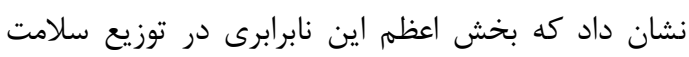
روان قابل اجتناب است و مى توان آن را كاهش داد زيرا

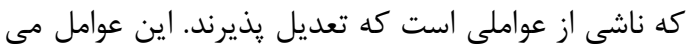

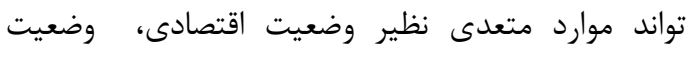

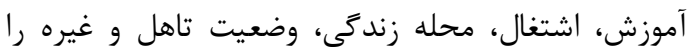
شامل گردد كه در مطالعه ما اثر آنها مورد بررسى قرى مرار نَخرفت.
متغير هاى كنترل سبب كاهش بيشتر در سمهم متغير هاى دموگرافيك (نابرابرى غير قابل جبران) در توزيع نابرابر

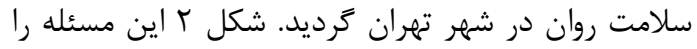
به خوبى نشان داده است. بحث در مطالعه حاضر محققين نابرابرى قابل اجتناب اقتصادى و اجتماعى در توزيع سلامت روان در شهر تهران را مورد بررسى قرار دادند. يافته هاى مطالعه نشان داد كه در شهر

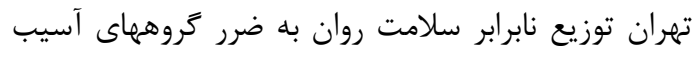


در توزيع اقتصادى عوامل دموكرافيك باشد و اينكه توزيع متغير هاى دموكرافيك در ميان گروههاى اقتصادى در درائر

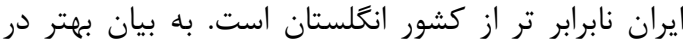

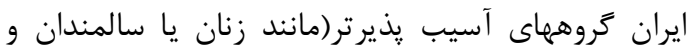

غيره) بيشتر در نيمه پايينى توزيع درآمدى قرار دارند.

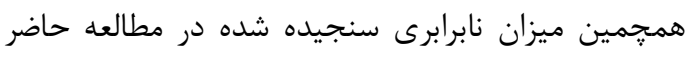

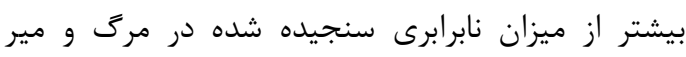

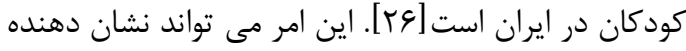
اين باشد كه به دليل تلاش هاى قابل توجه صورت كر كرفته

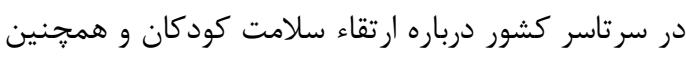

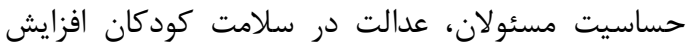
يافته است ولى ما شاهد جنين موضوعى در سلامت روان دران

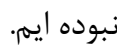

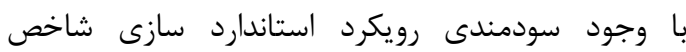
تجمعى بايد دقت نمود كه هدف از استاندارد سازى ايجاد

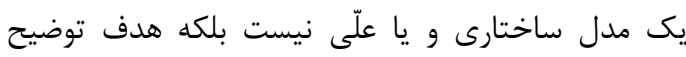

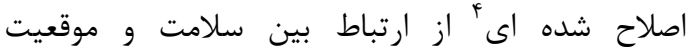

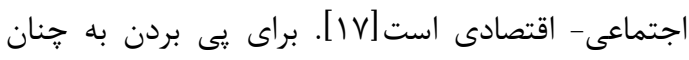

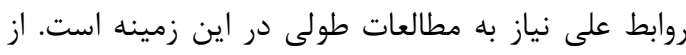
محدوديت هاى ديگر مطالعه حاضر وجود بيشتر تعداد زنان نسبت به مردان در مطالعه مى باشد. در حقيقت دردان

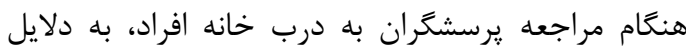

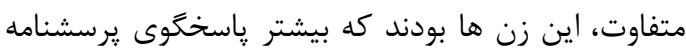
ها بودند. تاثير اين مسئله در تفسير نتايج بايد در نظر

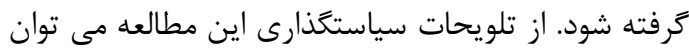

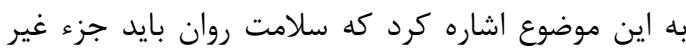

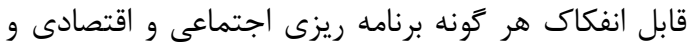

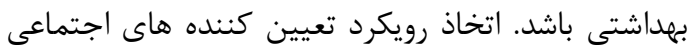

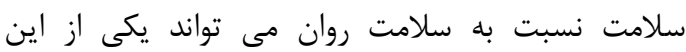

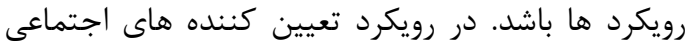

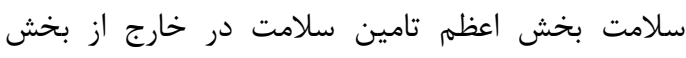

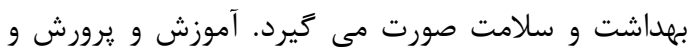
نظام آموزش در كل، مسكن، برنامه ريزى شهرى و تامين

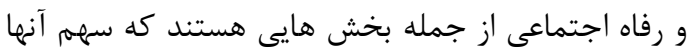

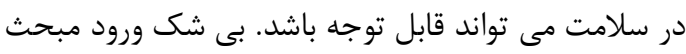

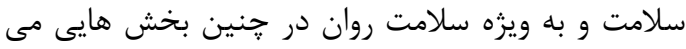

\section{Refined}

البته بايد توجه داشت كه اثر هر متغير بر روى توزيع

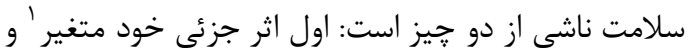

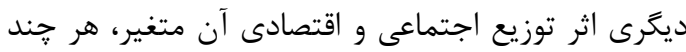

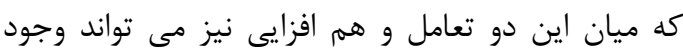

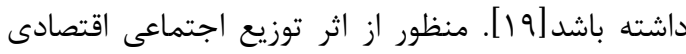

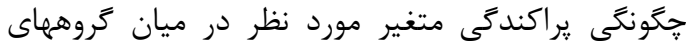

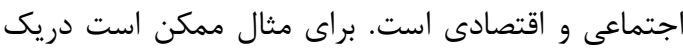

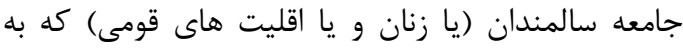

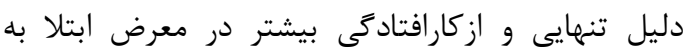

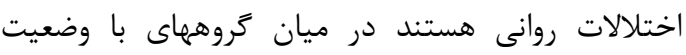

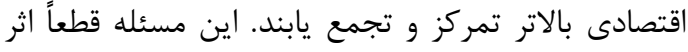

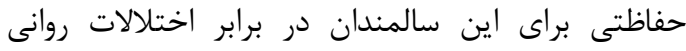

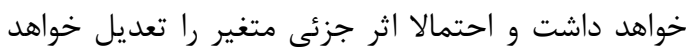

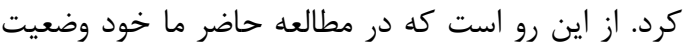

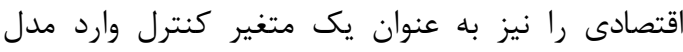

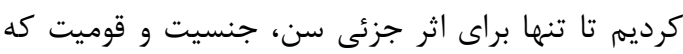

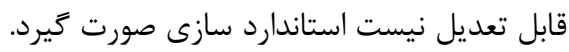

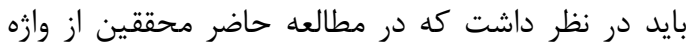

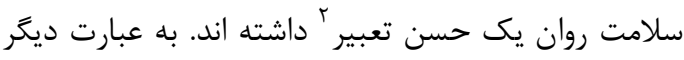
اگرجه ما به دنبال بررسى توزيع اختلالات روانى در شهر

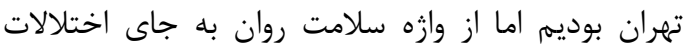
روانى استفاده كرده ايم.

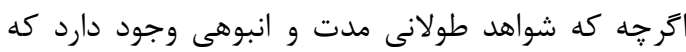

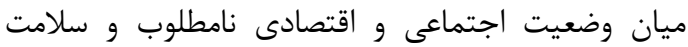

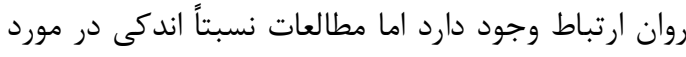

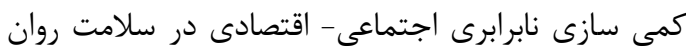

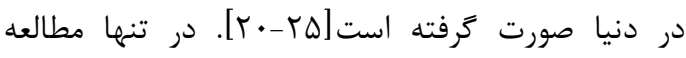

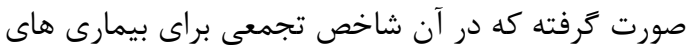

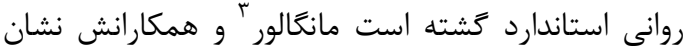
دادند كه بخش اعظم نابرابرى اقتصادى- اجتماعى در

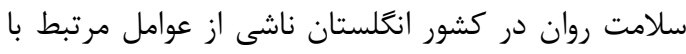

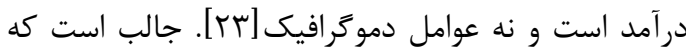
در مطالعه آنها سهم عوامل دموكرافيك در نابرابرى كمتر

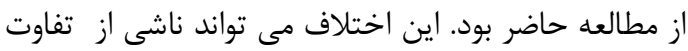

1.Marginal effect

2. Euphemism

3 .Mangalore 
هستيم. شايد اين امر يكى از بزرَترين خالش هاى نظام سلامت ما باشد. نتيجه گَيرى سلامت روان در شهر تهران به طور نابرابرى توزيع گشته

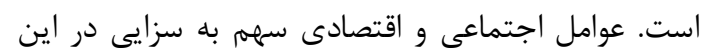

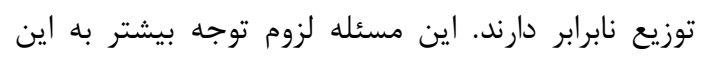

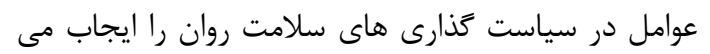
كند.

\section{References}

1. World Health Organization, Investing in mental health, World Health Organization publication, Geneva, Switzerland, 2003.

2. World Health Organization,The global burden of disease: 2004 update, World Health Organization Publication, Geneva. Switzerland, 2008.

3. World Health Organization, Promoting mental health: concepts, emerging evidence, practice, Summary report, Department of Mental Health and Substance Abuse in collaboration with the Victorian Health Promotion Foundation (Vic Health) and the University of Melbourne, World health organization Publication. Geneva. Switzerland, 2004.

4. Noorbala, AA,BagheriYazdi, SA, Yasamy MT et al, Mental health survey of the adult population in the Islamic Republic of Iran, British journal of psychiatry, 2004:, 184, 70-73.

5. Naghavi M, Abolhassani F, Pourmalek $\mathrm{F}$, et al, The burden of disease and injury in Iran 2003. Population Health Metrics 2009.

6. Lorant V. Delige, Socioeconomic Inequalities in Depression: A Meta-Analysis, American Journal of Epidemiology, 2003 ,157: 98-112.

7. Pickering J. Is wellbeing local or global? A perspective from ecopsychology, In: Haworth J, Graham H. Wellbeing: individual, community and social perspectives, Basingstoke, Palgrave Macmillan, 2007149162 .

8. Braveman, P. Health disparities and health equity: concepts and measurement, Annual Review of Public Health, 2006, 27: 167-94.
تواند در ارتقاء سلامت و همجنين عدالت در سلامت بسيار

مفيد باشد. در حقيقت اين بخش ها مى توانند توزيع افراد

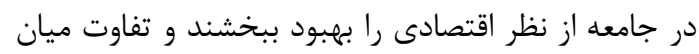

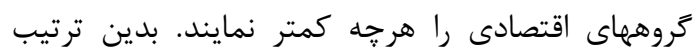

تاثير منفى متغير هاى اجتماعى بر سلامت كه ناشى از

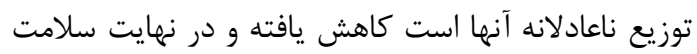

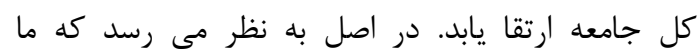

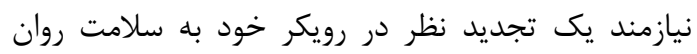

9. Friedli, L. Mental health, resilience and inequalities, WHO Regional Office for Europe Publication, Copenhagen, Denmark. 2009

10. Blaxter M. 2004. Health, Polity Press, First Edition, 104-105.

11. Asadi-Lari M, Vaez-Mahdavi MR, Faghihzadeh S, Montazeri A, Farshad A, Kalantari N, Maher A, Golmakani MM, Salehi GH, Motevallian SA, Malekafzali H: The Application of Urban Health Equity Assessment and Response Tool (Urban HEART) in Tehran; concepts and framework. Medical Journal of Islamic Republicof Iran 2010, 24:175-185.

12. Noorbala AA, Mohammad K, BagheriYazdi SA: The Validation of GHQ-28 as a psychiatric screening tool. Hakim Magazine 2006, 5:101-110.

13. Vyas S, Kumaranayake L: Constructing socio-economic status indices: how to use principal components analysis. Health Policy Plan 2006, 21:459-468.

14. Filmer, D, \& Pritchett, L H (2001): Estimating wealth effects without expenditure data or tears: with an application to educational enrollments in states of India. Demography, 38, 115-132.

15. Kakwani N, Wagstaff A, Van Doorslaer E: Socioeconomic inequalities in health: measurement, computation, and statistical inference. Journal of Economics, 1997, 77:87103.

16. Kakwani $\mathrm{N}$ : Income inequality and poverty: methods of estimation and policy applications New York: Oxford University Press; 1980.

17. O'Donnell O, Van Doorslaer E, Wagstaff A, Lindelow M: Analyzing Health Equity Using Household Survey Data; a guide 
to techniques and their implementation Washington D C: The World Bank; 2008.

18. StataCorp: Stata Statistical Software: Release 10 College Station: StataCorp LP; 2007.

19. Harper S \& Lynch J: Commentary: Using innovative inequality measures in epidemiology. International Journal of Epidemiology 2007;36:926-928.

20. Patel V, Lund C, Hatherill S, Plagerson S, Corrigall J, Funk M, Flisher AJ: Mental disorders: equity and social determinants. In Equity, Social Determinants and Public Health Programs.Edited by: Blas A, Kurup AS. Geneva: WHO Press; 2010:115-134.

21. Wildman J: Income related inequalities in mental health in Great Britain: analyzing the causes of health inequality over time. Journal of Health Economics 2003, 22:295-312.

22. Costa-Font J, Gil J: Would socioeconomic inequalities in depression fade away with income transfers? Journal of happiness studies 2008, 9:539-558.

23. Mangalore R, Knapp M, Jenkins R: Income related Inequality in mental health in
Britain: the concentration index approach. Psychological Medicine2007, 37:1037-1045.

24. Mangalore R, Knapp M: Income-related inequalities in common mental disorders among ethnic minorities in England. Social Psychiatry Psychiatry and Epidemiology 25. Hong J, Knapp M, McGuire A: Incomerelated inequalities in theprevalence of depression and suicidal behavior: a 10-year trend following economic crisis. World Psychiatry 2011, 10:40-44.

26. Hosseinpoor AR, Van Doorslaer E, Speybroeck N, Naghavi M, Mohammad K, Majdzadeh R, Delavar B, Jamshidi H, Vega J: Decomposing socioeconomic inequality in infant mortality in Iran. International Journal of Epidemiology 2006, 35:1211-1219. 


\title{
Avoidable socioeconomic inequality in mental health distribution in Tehran: Concentration Index standardization approach
}

\author{
Khedmati Morasae $E^{1}$, Asadi Lari $M^{2}$, Setareh Forouzan $A^{3}$, Majdzadeh ${ }^{4}{ }^{4}$,Mirheidari $M^{5}$, Nabavi $S H^{6}$ \\ ${ }^{1}$ M.Sc of Social Welfare, Health Systems Research Center, Qom University of Medical Sciences and Health \\ Services, Qom, Iran \\ ${ }^{2}$ Associate professor of Epidemiology, Epidemiology and Biostatistics Department, Public Health School, \\ Tehran University of Medical Sciences, Tehran, Iran \\ ${ }^{3}$ Associate professor of Psychiatry, Center for Research on Social Determinants of Health, University of Social \\ Welfare and Rehabilitation Sciences, Tehran, Iran \\ ${ }^{4}$ Professor of Epidemiology, Knowledge Utilization Research Center (KURC), Tehran University of Medical \\ Sciences, Tehran, Iran \\ ${ }^{5}$ M.Sc of Health Education and Promotion, Qom University of Medical Sciences \\ ${ }^{6} \mathrm{M}$.Sc of Social Welfare, Addiction and Behavioural Science Research Center North Khorasan University of \\ Medical Sciences and Health Services, Bojnurd, Iran
}

*Corresponding Author:
Tehran University of Medical
Sciences, Public Health
School, Epidemiology and
Biostatistics Department.
Email:
mohsen.asadi@yahoo.com

Submitted:30 Aug 2012

Revised: 15 Oct 2012

Accepted:27 Nov 2012

\begin{abstract}
Background \& Objective: Widespread health inequalities are of grand challenges to health systems. In present study, researchers aimed to measure socioeconomic inequality in distribution of mental disorders in Tehran.

Material \& Methods: Required data were obtained from Urban HEART (Urban Health Equity Assessment and Response Tool) survey conducted by Municipality of Tehran in 2007. Sample was consist of 22135 people (over 15 years old) selected by systematic cluster sampling method. The Concentration index $(C)$ approach was applied to examine socioeconomic inequality in mental health in Tehran. Concentration index of mental health was demographically (age-sexethnicity) standardized in order to determine the level of avoidable inequality. In next step, to control for variables of education, occupation, marital status and economic status which might be related to mental health and demographic variables and prevent from inadvertent standardizing of these variables, these variables also were entered into model.

Results: Concentration index of mental health $(-0.0673,95 \%$ confidence interval $=-0.070-0.057)$ showed that, there is inequality unfavourable to poorer people in Tehran respecting mental disorders. When the distribution of mental disorders was standardized for demographic composition of the quintiles, the standardized C equalled 0.046 (95\% confidence interval $=-0.0522--0.0398$ ). This little drop suggests that demographic composition is not the main determinant of observed mental health inequality in Tehran. When they controlled for variables of employment and education, standardized $C$ increased and equaled $C I=-0.053$ (95\% confidence interval $=-0.059--0.047)$. Indeed, the last analysis led to more shrink in inequality attributable to demographics.

Conclusion: Since much of the observed inequality in mental health is probably due to social factors and not to demographic ones, therefore the possibility of inequality correction and its avoidance will increase Key words: Avoidable Inequality, Concentration Index, Mental Health, and Standardization
\end{abstract}

